\title{
Additive effects of exposure to silica dust and smoking on pulmonary epithelial permeability: a radioaerosol study with technetium-99m labelled DTPA
}

\author{
L E Nery, R T Florencio, P R M Sandoval, R T Rodrigues, G Alonso, G R Mason
}

\begin{abstract}
Background Increased pulmonary epithelial permeability evaluated by the rate of clearance from lung to blood of the radioaerosol solute technetium-99m labelled diethylenetriamine pentacetate ( ${ }^{99 \mathrm{~m}}$ Tc-DTPA) has been reported in smokers and in workers exposed to silica dust. A study was carried out to determine whether there are additive effects of cigarette smoke and exposure to silica dust on clearance rates of ${ }^{99 m}$ Tc-DTPA in ceramic workers.
\end{abstract}

Methods Thirty one subjects with silicosis were studied, of whom 18 smoked cigarettes and 13 were non-smokers. They had similar histories of exposure to silica dust, and radiological alterations consistent with silicosis. The results from these patients were compared with those from normal subjects and smokers previously studied by the authors.

Results Pulmonary function values were normal in most patients and not significantly different among groups. The median (range) rate of clearance of 99mTc-DTPA in smokers with silicosis was $4 \cdot 1(1 \cdot 9-12 \cdot 7) \% / m i n u t e$, which was higher than the rates in non-smoking patients with silicosis of $2 \cdot 2(1 \cdot 1-6 \cdot 6)$ $\% / m i n u t e$ and in smokers without exposure to silica dust of $2.9(1.6-4.5) \%$ / minute. These differences were more evident and significant when the clearance rates of the lower lobes of the three groups were compared. Clearance rates higher than $3 \% /$ minute were much more frequent in smokers with silicosis $(85 \%)$ than in non-smoking patients with silicosis $(15 \%)$ and in smokers $(40 \%)$.

Respiratory Medicine, Department of Medicine, Escola Paulista de Medicina, Sao Paulo, Brasil L E Nery

R T Florencio

P R M Sandoval

$\mathrm{R}$ T Rodrigues

G Alonso

Department of

Medicine, Harbor-

UCLA Medical

Center, Torrance,

California, USA

G R Mason

Reprint requests to: DrG R Mason

Accepted 18 August 1992 radiographic changes resulting from exposure to silica dust, there is an additive effect of inhalation of silica dust and cigarette smoking on clearance rates of $99 \mathrm{~m}$ Tc-DTPA.

(Thorax 1993;48:264-268)

Accelerated clearance rates of small inhaled radioaerosol solutes from the lung to the blood have been used as an index of pulmonary epithelial permeability in patients with acute and chronic respiratory disease. Increased rates of clearance of the radionuclide technetium-99m labelled diethylenetriamine pentacetate ( ${ }^{99 m}$ Tc-DTPA) have been reported in infants and adults with the respiratory distress syndrome ${ }^{12}$; in patients with Pneumocystis carinii pneumonia, ${ }^{3}$ systemic sclerosis, ${ }^{4}$ sarcoidosis, ${ }^{56}$ and idiopathic pulmonary fibrosis; ${ }^{6}$ and after cytotoxic agents $^{7}$ and amiodarone. ${ }^{8}$ Active cigarette smoking also causes an increase in alveolar epithelial permeability. ${ }^{50-12}$ We have recently reported that chronic exposure to silica dust may be related to accelerated clearance rates of this solute, even in the absence of radiographic changes. ${ }^{12}$ Since smoking and exposure to respirable free silica dust appear independently to injure the lungs and cause accelerated solute clearance rates, our purpose was to determine if there is an additive effect on ${ }^{99 \mathrm{~m} T c-D T P A}$ clearance rates in patients with silicosis who are smokers.

\section{Methods}

\section{SUBJECTS}

Subjects were selected from 150 ceramic workers $^{1314}$ who had had prolonged exposure to silica dust that exceeded the permitted threshold value for Brazil. ${ }^{15}$ In addition to the occupational history, chest radiographic abnormalities present in each patient confirmed the diagnosis of silicosis. Eighteen smokers with silicosis and 13 non-smoking patients with silicosis were studied, and were compared with a previously studied group of normal smokers and normal subjects not exposed to silica dust. ${ }^{12}$ Dust exposure, smoking histories, and anthropometric data were compared between the groups.

\section{PULMONARY FUNCTION TESTS AND CHEST} RADIOGRAPHS

Spirometric measurements including forced vital capacity (FVC), forced expired volume in one second $\left(\mathrm{FEV}_{1}\right)$ and forced expired flow between $25 \%$ and $75 \%$ of FVC $\left(\mathrm{FEF}_{25-75}\right)$ were analysed as percentages of predicted values. ${ }^{16}$ Chest radiographs were classified according to the ILO guidelines ${ }^{17}$ by a radiologist experienced in this method and two chest physicians, resulting in a consensus interpretation. The severity of radiographic abnormality was graded as mild if profusion 
scores were 1 and moderate if profusion scores were 2 or more.

PULMONARY EPITHELIAL PERMEABILITY

Samples of ${ }^{99 \mathrm{~m}}$ Tc-DTPA were prepared from kits from IPEN-CENEN (Sao Paulo, Brazil) diluted in $2 \mathrm{ml}$ saline containing more than $98 \%$ bound ${ }^{99 m}$ Tc-DTPA. The subject was seated with the back against an Anger gamma scintillation camera (Searle-LFOV) and $740 \times 10^{6} \mathrm{~Bq}(20 \mathrm{mCi})$ of the radioaerosol was inhaled.

The aerosol generating system has been described in detail previously. ${ }^{12}{ }^{18} \mathrm{~A}$ jet nebuliser with a flow rate of $10 \mathrm{l} /$ minute produces an aerosol that passes through a system of two plastic reservoirs that impacts and traps the large particles, resulting in droplets with a mean mass aerodynamic diameter of $1.1 \mu \mathrm{m}$ and a geometric standard deviation of $2 \cdot 69$. Particle distribution was measured with a Battelle 5 stage cascade impactor. ${ }^{12}$

Pulmonary radioactivity was measured in counts per minute in 20 second sequential frames during the two minute inhalation period and for 10 minutes thereafter. Data were stored and processed by computer. Digital images were produced on a colour monitor and eight regions of interest were selected. Six of the regions of interest, representing $20 \%$ of the posterior portion of each lung, were selected from the periphery of the upper, middle, and lower regions of each lung. ${ }^{6} 12$ The whole right and left lung regions were also analysed. Regional radioactivity was then plotted against time, and the clearance rate of ${ }^{99 m}$ T.c-DTPA from lung to blood was calculated in units of percentage decline/ minute for the first seven minutes of the postinhalation (washout) period. The negative slope of the logarithm of radioactivity against time on a linear scale was expressed as the clearance rate, $k$, in units of percentage decline/minute. ${ }^{61112}$ The clearance rate was calculated over a seven minute period to minimise the effect of rising activity in the lung tissue and blood pool. ${ }^{6}$ The total clearance rate of both lungs was calculated as the mean rates of the right and left lungs.

This study was approved by the Ethics Committee of Escola Paulista de Medicina

Mean (SE) anthropometric characteristics, smoking history, dust exposure, and pulmonary function tests in the three groups

\begin{tabular}{lccc}
\hline & $\begin{array}{l}\text { Smokers } \\
\text { with silicosis }\end{array}$ & $\begin{array}{l}\text { Non-smokers } \\
\text { with silicosis }\end{array}$ & Smokers \\
\hline Age (years) & $40(2 \cdot 1)$ & $41(2 \cdot 1)$ & $27(1 \cdot 2)^{\star}$ \\
Weight (kg) & $74(1 \cdot 4)$ & $73(2 \cdot 7)$ & $70(3 \cdot 8)$ \\
Height (cm) & $172(1 \cdot 8)$ & $169(1 \cdot 2)$ & $174(2 \cdot 8)$ \\
Dust exposure (years) & $16 \cdot 1(1 \cdot 7)$ & $19 \cdot 4(1 \cdot 9)$ & - \\
& & & \\
Smoking history: & $18 \cdot 2(1 \cdot 6)$ & - & $21 \cdot 0(1 \cdot 8)$ \\
$\quad$ cigarettes/day & $20 \cdot 4(2 \cdot 6)$ & - & $9 \cdot 7(1 \cdot 7)^{\star \star}$ \\
packs/year & $98(2 \cdot 0)$ & $94(4 \cdot 4)$ & $95(3 \cdot 0)$ \\
FVC (\% pred) & $99(1 \cdot 86)$ & $98(5 \cdot 4)$ & $94(2 \cdot 5)$ \\
FEV $_{1}$ (\% pred) & $88(5 \cdot 8)$ & $99(11 \cdot 0)$ & $98(10 \cdot 0)$ \\
FEF $_{25}$ i5 (\% pred) & & & \\
\hline
\end{tabular}

FVC - forced vital capacity; $\mathrm{FEV}_{1}$ - forced expired volume in one second; $\mathrm{FEF}_{25-75}$ forced expired flow between $25 \%$ and $75 \%$ of the FVC; \% pred-percentage of the predicted value. ${ }^{1}$

${ }^{\star}$ Smokers < smokers with silicosis and non-smokers with silicosis (ANOVA).

$\star \star$ Smokers $<$ smokers with silicosis (unpaired $t$ test) and informed consent was obtained from all subjects. The radiation dose received by each subject for the radioaerosol study and chest radiographic evaluation was $0.35 \mathrm{mSv}$.

\section{STATISTICS 1920}

The anthropometric data and pulmonary function values were analysed by completely randomised analysis of variance (ANOVA) to compare the same variable in the three groups. The Scheffé multiple comparison test was then used to detect the mean values that contributed to the significant $F$ values. Unpaired $t$ tests were used to compare exposure to silica dust and to cigarette smoking between the groups.

As the data were not normally distributed in patients, non-parametric statistics were used in the analysis of regional lung activities and clearance rates of ${ }^{99 \mathrm{~m}} \mathrm{Tc}-\mathrm{DTPA}$. The Kruskal-Wallis one way analysis of variance by ranks was used to compare the same variable in the three groups, and the Dunn multiple comparison test was then used to identify the differences between groups. The Wilcoxon signed rank test was used to compare paired data and the $\chi^{2}$ statistic to test association. Values of $p<0.05$ were considered significant. To determine whether the degree of abnormality on the chest radiograph was associated with more rapid clearance rates of ${ }^{99 m}$ Tc-DTPA results in both smoking and non-smoking patients with silicosis with mild chest radiographic scores were compared with patients in the same group with more abnormal chest radiographic findings.

\section{Results}

While the smokers were younger than the patients with silicosis, no differences in weight and height were found between the groups. The smoking habits of subjects with and without silicosis were similar at the time of the study $(18.2(1.6)$ and 21.0 $(1 \cdot 8)$ cigarettes/day respectively), although the former had a higher cumulative smoking history. Both groups had similar exposures to an atmosphere of respirable dust containing free silica. Spirometric variables were within the normal range, and no differences among groups were observed (table).

Small opacities up to $10 \mathrm{~mm}$ in diameter and profusion $1 / 1$ to $3 / 3$ were present on the chest radiographs in both smoking and nonsmoking patients with silicosis. Mild abnormalities ( $\mathrm{p} / \mathrm{p} 1 / 1)$ were present in nine non-smoking and 10 smoking patients with silicosis, and moderate abnormalities occurred in four non-smoking patients with silicosis (p/q $2 / 2$ (two patients), p/p 2/2, and $\mathrm{p} / \mathrm{p} 3 / 3$ ) and in eight smoking patients with silicosis (p/p 2/2 (three patients), $\mathrm{q} / \mathrm{r} 3 / 3, \mathrm{t} / \mathrm{t}$ $2 / 2, \mathrm{q} / \mathrm{r} 2 / 2, \mathrm{p} / \mathrm{q} 2 / 2$, and $\mathrm{q} / \mathrm{q} 3 / 3$ ).

Pulmonary radioactivity was higher in the lower than the upper region in all subjects. A similar regional radioaerosol clearance distribution (ratio of the radioactivity in each region of interest/total radioactivity) was found in the three groups (fig 1). The average 

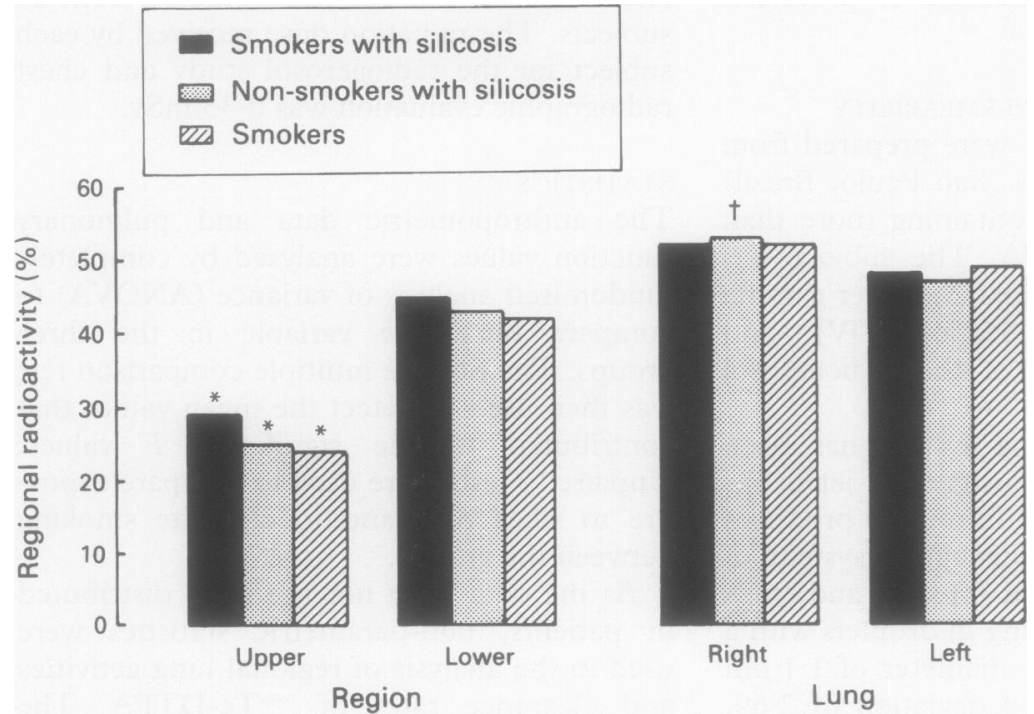

Figure 1 Regional radioactivity of ${ }^{99 m} T c-D T P A$ defined as the activity in each region of interest/total activity in that lung. ${ }^{\star} p<0.05$, upper $<$ lower region; $p<0.05$ right versus left lung. - - - -

clearance rates of ${ }^{99 m}$ Tc-DTPA in smokers with silicosis were faster than in non-smoking patients with silicosis and in smokers. Smokers as a group, and all smokers with silicosis, were abnormal but not different from each other; however, the smokers with silicosis were significantly worse than the nonsmokers with silicosis (fig 2).

The mean regional clearance rate of ${ }^{99 \mathrm{~m}} \mathrm{TC}-$ DTPA was significantly faster in the upper than the lower region in smokers, while there was no difference between upper and lower lung fields in either smoking or non-smoking patients with silicosis (fig 3).

The mean clearance rate in non-smoking patients with silicosis whose chest radio-

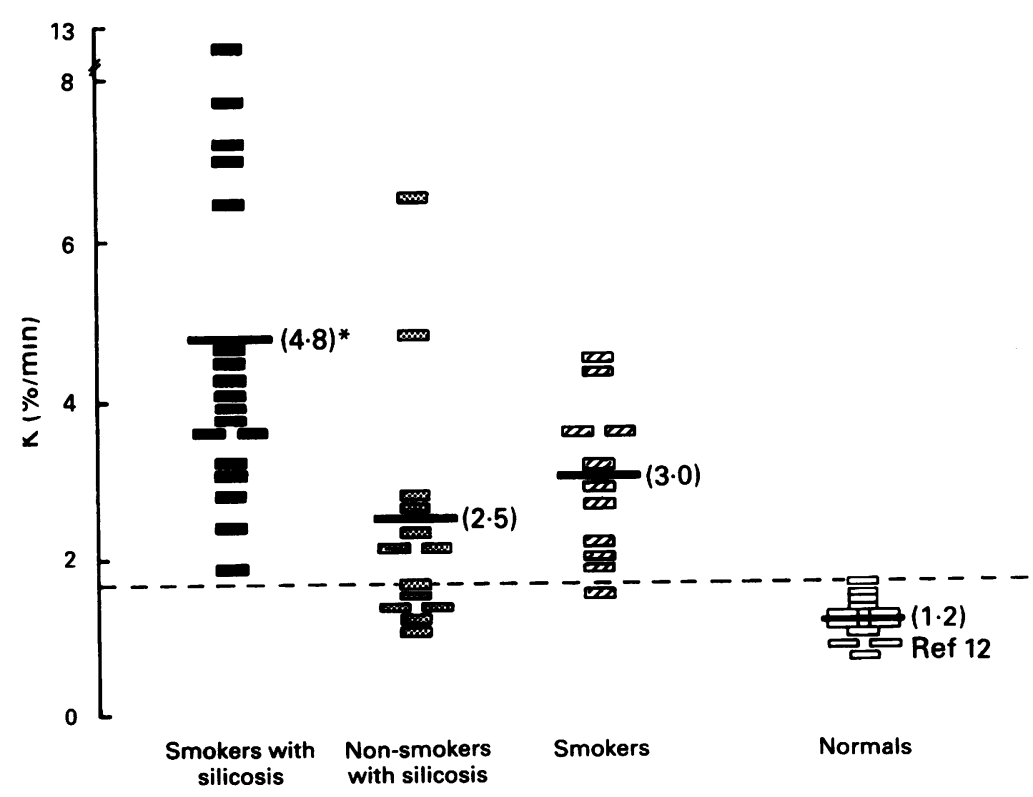

Figure 2 Individual and mean values of ${ }^{99 m}$ Tc-DTPA clearance rates, $k$ (inclusive of all lung fields), in smokers with silicosis, non-smokers with silicosis and smokers compared with normal values. ${ }^{2}$ The dashed line represents the highest rate of clearance of the normal group. ${ }^{*} p<0.05$ compared with non-smokers with silicosis.

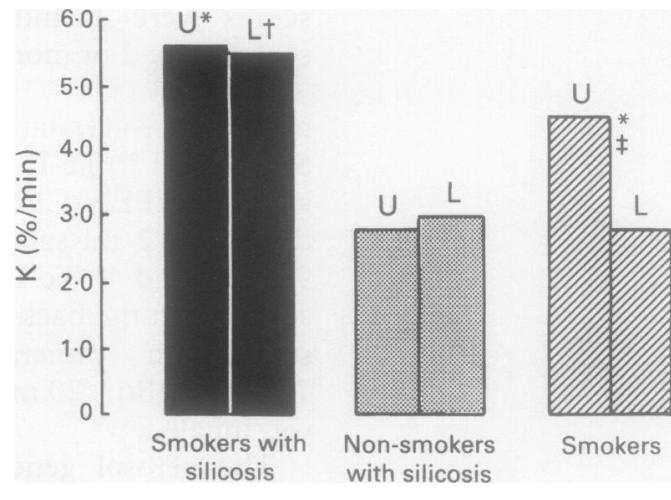

Figure 3 Upper $(U)$ and lower $(L)$ mean clearance rates of ${ }^{99 m}$ T $C-D T P A$ in the three groups. ${ }^{*} p<0.05$ (upper region): smokers with silicosis and smokers $>$ non-smokers with silicosis; ${ }^{*} p<0.05$ (lower region): smokers with silicosis > non-smokers with silicosis and smokers; $\ddagger p<0.05$ : upper versus lower region.

graphic abnormalities were classified as mild was $2 \cdot 7 \% /$ minute, which was not different from those classified as of moderate severity in whom the clearance rate was $2 \cdot 0 \%$ /minute. Similarly, the mean clearance rate in smokers with silicosis with mild radiographic abnormalities was $5 \cdot 0 \%$ /minute, which was not different from those with a classification of moderate severity, whose clearance rate was $4.6 \% /$ minute.

\section{Discussion}

Smokers have faster clearance rates of ${ }^{99 \mathrm{~m} T c-}$ DTPA from the lungs than non-smokers, an effect which is more pronounced in the upper lung regions. 911 We have previously shown that the aerosol clearance rate of ${ }^{99 \mathrm{~m}} \mathrm{Tc}$ DTPA in non-smoking normal subjects averages $1.2 \% /$ minute with a range of $0 \cdot 8-1 \cdot 7 \% /$ minute. ${ }^{12}$ Workers exposed to silica dust may have accelerated clearance rates, with or without radiographic changes. ${ }^{12}$ Gellert and coworkers reported similar findings in subjects exposed to asbestos. ${ }^{21}$ The present study indicates that these effects of smoking and silica dust are additive.

Approximately $80 \%$ of the particles inhaled by humans are deposited in the lung periphery-this has been interpreted to be the small airways and alveoli. ${ }^{22}$ Uncertainty remains about the precise deposition of aerosol droplets that are likely to gain water and increase in size. As our subjects had similar regional radioactivity distributions (fig 1) and there were no differences in pulmonary function indices between groups, different deposition is an unlikely explanation for our results. Differences in distribution of ventilation, blood flow, inequalities of ventilation/ perfusion, and the level of alveolar deposition are not critical factors affecting the clearance rates of ${ }^{99 m}$ Tc-DTPA. ${ }^{6923-25}$

Recirculation of the radiotracer within the chest wall and vessels may lead to an underestimation of the clearance rate. This observation was reported when the calculation was performed 20-30 minutes after inhalation in 
subjects with faster clearance rates. ${ }^{9}$ Background correction is used by some investigators by simultaneously determining relative activity of the thorax and thigh following intravenous administration of ${ }^{99 \mathrm{~m}} \mathrm{Tc}-$ DTPA, ${ }^{1026}$ or by measuring background activity in the interrenal area. ${ }^{21} 27 \mathrm{We}$ did not use background correction for recirculation, but determined the clearance over the first seven minutes after inhalation to minimise effects of rising radioactivity in the chest wall, lung tissue, and vascular tree. ${ }^{611} 12$

Since the first report by Jones et al ${ }^{10}$ it has been shown that smokers have a faster pulmonary clearance rate of ${ }^{99 \mathrm{~m}} \mathrm{Tc}-\mathrm{DTPA}$, which is not related to spirometric abnormalities or gas exchange. ${ }^{91112}$ Accelerated clearance rate was related to the amount smoked in the preceding days ${ }^{1128}$ rather than to the total tobacco consumption. Faster clearance rates occur in the upper than in the lower lung regions when studies are performed in the upright position, ${ }^{112}$ possibly as a result of greater "stretching" of epithelial pores in the lung apices. In smokers an additional consideration is the effect of inhaled smoke, which, according to the mechanisms of gas distribution, stays longer in the distended apical alveoli and may cause relatively greater changes in these membranes. ${ }^{929}$

The pulmonary clearance rate of $99 \mathrm{~m} \mathrm{Tc}-$ DTPA in patients with pneumoconioses was first evaluated by Rinderknecht et al, ${ }^{6}$ who found faster clearance rates in two of three patients exposed to silica dust. We reported abnormal clearance rates in non-smoking subjects exposed to silica with normal or abnormal radiographic findings. ${ }^{12}$ Isolated exposure to silica is sufficient to cause abnormal clearance rates of DTPA as seven of 13 non-smoking patients with silicosis had clearance rates greater than the highest clearance rate measured in the normal group. Cigarette smoke and silica cause quite different pathological changes in the lung, and the former injury is rapidly reversible on stopping smoking. We therefore examined whether the patterns of clearance differed between these types of injury (fig 3). In contrast to normal subjects and smokers, both groups of patients with silicosis lost the normal pattern of greater upper lobe than lower lobe clearance. It may be that more widespread abnormalities of DTPA clearance patterns in smokers with silicosis (compared with cigarette smokers without silicosis) are the result of different disposition patterns of the inhaled silica dust particles. ${ }^{12}$ Another possibility is disruption of the normal distribution of blood volume, with less recirculation in the apices when studies are performed on normal subjects when seated. In patients with silicosis, scarring of the lung parenchyma may result in the loss of the normally greater blood flow to the bases, a situation unlikely to occur in smokers.

Clinical and epidemiological studies have suggested that silica dust and smoking are additive risk factors leading to chronic bronchitis and chronic airways obstruction. ${ }^{30}$ The analysis of individual data reinforces this theory, showing that clearance values greater than $3 \% /$ minute were much more frequent in smokers with silicosis (83\%) than in nonsmokers with silicosis $(15 \%)$ or in those not exposed to silica dust (40\%) (fig 2).

This study shows an additive effect of smoking and exposure to silica dust in increasing epithelial permeability in patients with silicosis who smoke. There was a wide range of radiographic abnormalities, and it might have been expected that prior inflammatory changes may have led to more severe anatomical and physiological abnormalities. It is perhaps surprising therefore that the degree of abnormality found on radiographs was not correlated with the abnormalities of DTPA clearance seen in both smoking and nonsmoking patients with silicosis.

Prospective studies will be necessary to understand the prognostic implications of these observations. If, as suggested in the literature, ${ }^{7132021}$ clearance rates of ${ }^{99 m}$ Tc-DTPA reflect injury to the pulmonary membranes from active inflammation and interstitial lung diseases, smokers with silicosis may be more likely to progress to a complicated form of the disease. This study reinforces the idea that control of smoking is important in minimising the respiratory consequences of silica related illness in exposed working populations. ${ }^{30}$

This research was supported in part by the Brazilian Agency for Research Development (CNPq, No. 30063/79). The authors thank Helena Hiroko Ikeda for the technical assistance at Division of Nuclear Medicine of Laboratorio Fleury; Dr Manfredo Tabacanicz for the measurement of the aerodynamic diameter of the radioaerosol particles; Drs Neil F Novo and Yara Juliano for statistical analysis, and Eunice Akyama for the secretarial help in preparing this manuscript.

1 Jefferies AL, Coates G, O'Brodovich H. Pulmonary epithelial permeability in hyaline-membrane disease. $N$ Engl f Med 1984;311:1075-80.

2 Mason GR, Effros RM, Uszler JM, Mena I. Small solute clearance from the lungs of patients with cardiogenic and non-cardiogenic pulmonary edema. Chest 1985 88:327-34

3 Mason GR, Duane GB, Mena I, Effros RM. Accelerated solute clearance in Pneumocystis carinii pneumonia. Am Rev Respir Dis 1987;135:864-6

4 Chopra SK, Taplin GV, Tashkin DP, Elam D. Lung clearance of soluble radioaerosols in systemic sclerosis. Thorax 1979;34:63-7.

5 Jacobs MP, Baughman P, Hughes J, Fernandes-Uloa $M$. Radioaerosol lung clearance in patients with active pulmonary sarcoidosis. Am Rev Respir Dis 1985;131:687-9.

6 Rinderknecht J, Shapiro, L, Krauthammer M, Taplin G, Wasserman K, Uszler JM, et al. Accelerated clearance of small solutes from the lungs in interstitial lung disease. Am Rev Respir Dis 1980;121:105-17.

7 O'Doherty MJ, Van De Petter JEW, Page $\mathrm{CH}$, Bateman NT, Singh AK, Croft D. Pulmonary permeability in hematologic malignancies. Cancer 1986;58:1286-8.

8 Terra Filho M. Estudo com radioaerosol de DTPA Tecnecio$99 \mathrm{~m}$ em pacientes portadores de pneumopatia por amiodarona. Thesis submitted to the Departmento de Cardio-Pneumologia da Faculdade de Medicinea da Universidade de Sao Paulo, 1989.

9 Dusser DJ, Minty BD, Collingon MAG, Hinge D, Barriault LG, Huchon GJ. Regional respiratory clearance of aerosolized ${ }^{99 \mathrm{~m} T c-D T P A}$ : posture and smoking effects. F Appl Physiol 1986;60:2000-6.

10 Jones JG, Lawler P, Grawley JCS, Minty GD, Hulands G, Veall $\mathrm{N}$. Increased alveolar epithelial permeability in cigarette smokers. Lancet 1980;i:66-8.

11 Mason GR, Uszler JM, Effros RM, Reid E. Rapidly reversible alterations of pulmonary epithelial permeability induced by smoking. Chest 1983;83:6-11.

12 Nery LE, Sandoval PRM Jardim JRB, Bagatin E, Alonso G. The effects of smoking and silica exposure on pulmonary epithelial permeability: a radioaerosol study with ${ }^{99 m}$ Tc-DTPA. Brazilian $f$ Med Biol Res 1988; 21:223-32.

13 Bagatin E, Oliveira JCA, Rodrigues RT, Greco L, Jardim 
JRB. Avaliacao clinica, radiologica e de funcao pulmonar em 95 individuos expostos a poeira de silica por mais de 20 anos. $\mathcal{F}$ Pneumol 1984;10:276S.

14 Florencio RT, Nery LE Campos LB, Bagatin E, Jarim JRB, Santos ML. Testes de exericio na avaliacao functional de ceramistas com silicose pulmonar. Rev Bras Saude Ocupacional 1989;65:33-42.

15 Mendes R, Puelma, HD, Alice SH. Doencas profissionais causadas por poeiras-silicose. In: Mendes R, ed. Medicina do Trabalho-Doencas Profissionais. Sao Paulo Sarvier: 1980:129-96.

16 Morris JF. Spirometry in the evaluation of pulmonary function. West $\mathcal{F}$ Med 1976;125:110-20.

17 International Labour Office (ILO). Classification of radiographs of the pneumoconioses. Medical Radiography and Photography 1981;57:2-17.

18 Martins LR, Takaoka K, Carlini E, Alonso G, Fernandes, Romaldini $\mathrm{H}$. Lung inhalation scintigraphy; development of a new aerosol system. Nucl Med Commun 1985;6:389-95.

19 Bruning JL, Kintz BL. Computational handbook of statistics. Glenview: Scott and Foresman, 1977.

20 Hollander M, Wolfe DA. Non-parametric statistical methods. John Wiley and Sons, 1973

21 Gellert AR, Langford JA, Winter RJD, Lewis CA, Tolfree SEJ, Rudd RM. Clearance of technetium-labelled DTPA in asbestos exposed subjects without clinical or radiological evidence of interstitial lung disease. $\mathrm{Br} \mathcal{F} \mathrm{Di}$ Chest 1985;79:37-42.

22 Chamberlain MJ, Morgan WKC, Vinitski S. Factors influ- encing the regional deposition of inhaled particles in man. Clin Sci 1983:64:69-78.

23 Coates G, O'Brodovich H. Measurements of pulmonary epithelial permeability with ${ }^{99 \mathrm{~m}}$ Tc-DTPA aerosol. Semin Nucl Med 1986;16:275-84

24 Effros RM, Mason GR Measurements of pulmonary epithelial permeability in vivo. Am Rev Respir Dis 1983;127:59-65S

25 Rizk NW, Luce JM, Hoeffel JM, Price DC, Murray JF. Site of deposition and factors affecting clearance of aerosolized solute from canine lungs. $f$ Appl Physiol 1984;56:723-9.

26 Jones JG, Royston D, Minty BD. Changes in alveolar capillary barrier function in animals and man. $A m$ Rev Respir Dis 1983;127:51-9S

27 Gellert AR, Lewis CA, Langford JA, Tolfree SEJ, Rudd RM. Regional distribution of lung epithelial permeability in normal subjects and in patients with asbestosis. Thorax 1985;40:734-40.

28 Jones JG, Minty BD, Royston D, Royston JP. Carboxyhemoglobin and pulmonary epithelial permeability in man. Thorax 1983;38:129-33.

29 Pearson MG, Vinitski S, Chamberlain MJ, Morgan WKC. Regional deposition of particles in the lung during cigarette smoking. Thorax 1984;39:716.

30 US Department of Health and Human Services. The health consequences of smoking. Cancer and chronic lung disease in the workplace. A report of the Surgeon General. Washington, DC: US Government Printing Office, 1985. DHHS Publication No (PHS) 85-50207. 